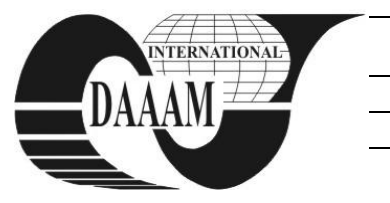

\title{
BLACK PRINTER NEUTRALS DISTRIBUTION USING K AND CMY COMPONENTS
}

\author{
AGIC, D[arko]; MANDIC, L[idija]; STRGAR KURECIC, M[aja]; POLJICAK, A[nte] \& AGIC, A[na]
}

\begin{abstract}
In this paper possible CMY and $K$ combinations of coverages as reproduction curves for selected profile are discussed, in the means of achieving related neutral optical output. Graphic arts reproduction basic subtractive primaries are extended with carbon black, meaning black printer. Its feature is to enhance reproducted picture quality, as well as to evaluate technical procedures. Modulation of lightness in neutrals as well as saturated colors, combining primaries and black lead to various facilities of possible tone reproduction curves, in addition to printing reproduction features.
\end{abstract}

Key words: black printer, achromatic reproduction, colorimetry

\section{INTRODUCTION}

For graphic reproduction purposes, as a result of the separation process of the coloured original, separations of subtractive primaries are achieved as separations films, printing plates, or direct imaged to the digital output system. When reproduced, each separation applies one of the primaries, creating coloured image within the reproduction. Mixed all three subtractive primaries, the result should be theoretically black (or achromatic), that respond satisfies in color photography due to relative high saturation of primaries, but in practical printing experience besides subtractive primaries, black (ink), mostly as carbon black, is added as a fourth printing form. When deploying, adjusting or balancing the reproduction process, it is common to trace and monitor the neutral scale and gray balance, as primary or initial characteristic important for the process.

\section{THE BLACK PRINTER}

The purpose of additional supported black ink and its application into the multicolor printing process encloses various features According to separation principles, separated color is imaged to the separation system in the same way as black, and other are imaged as white (Blair, 1983.). It means that areas on the printing form imaged "as black" will be dye transfering for the selected primary color. In graphic reproduction process the forth color, black, as the fourth separation (printing form) is appended to primary color separations, forming autotypic color process. Graphic arts reproduction basically applies two shapes of reproduction black ink curves (Yule, 2000.): skeleton black (KS) and full black tonal range (KF), as shown in fig 1 . The usage depends on various factors, such as technical properties of the reproduction process, reproduction of tones and colors mostly in highlights and midtones, and as possible dedicated demands in achromatic (black and white) reproduction.

\section{EXPERIENCE OF BLACK}

When discussing of black and white, in printing systems white corresponds to the niveau (of whiteness) of the substrate, and black is expressed as possible or maximum coverage of black ink $(\mathrm{K})$, or corresponding $\mathrm{CMY}+\mathrm{K}$ inks coverage combination. The situation of gray scale is considered as the area from light of low reflecting part (black), to reflectance of all wavenlenghts (whiteness of substrate). When interpreting perceived experience of tones and colors, in technical measuring means, this can be described as (colorimetric attributes) lightnes, corresponding values in RGB or HSB systems, as densitomeric $D_{r}, D_{g}, D_{b}$ values, and possible coverages of cyan, magenta, yellow and black inks ( $\hat{a}_{C}, \hat{a}_{M}, \hat{a}_{Y}$, $\left.\hat{a}_{\mathrm{K}}\right)$. When applying color managemrnt to reproduction illuminant characteristics, profiles and input-output device properties have to be taken in consideration.

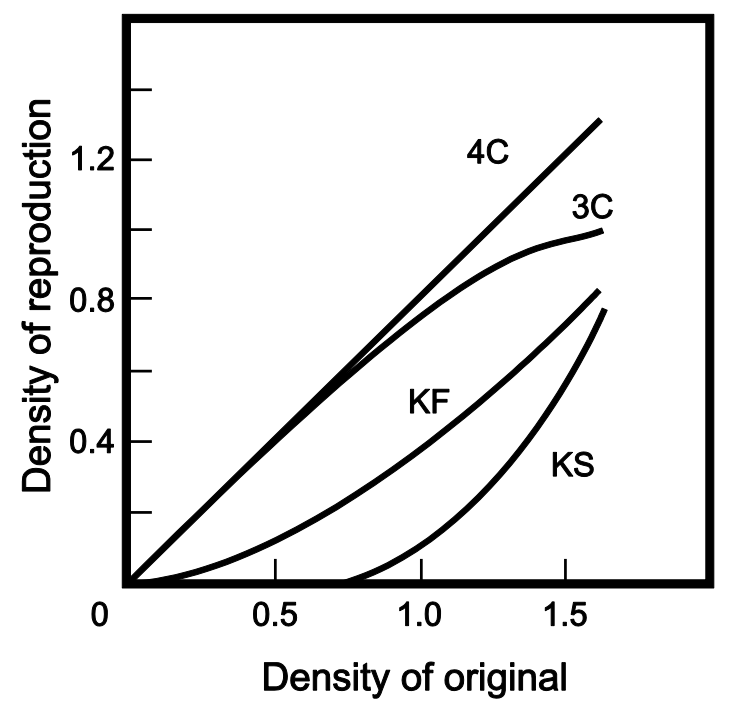

Fig 1. Characteristic shapes of reproduction curves: $4 \mathrm{C}$ denotes four color reproduction (CMYK), 3C three color reproduction (CMY), KF full tonal range black, KS skelet black (shematic view).

\section{GRAY SCALE AND TONAL SHIFT}

Black or specifically carbon black as printing inks pigment expresses an absorption mainly equable through the whole visible spectrum. Such a characteristic of black ink enables rather simple generating gray scale or lightness by color modulation with black halftoning/printing elements ( $\hat{a}_{K}$ coverage). In such containment hue shifts are rather minimalized, and the picture reproduction is conditionally stable. Such considerations are also rooting to achromatic reproduction methods, often linked to to TAC (total area coverage) calculations, specified by ISO 12647 regulations.

According to subtractive principles equal combination of primaries should generate neutrals (on achromatic scale). Unfortunatelly, equal C, M, Y coverages of real dyes in actual reproduction process can not be directly used. The combination has to support some further reproduction process parameters such as gray balance, white point and illuminant facilities. The term END (equivalent neutral density) describes the situation of 
generating neutral scale with C, M Y coverages (or expressed as related densities) for the proposed reproduction system and conditions, fig. 2, while the CMY ratio is defined as grey balance (Hunt, 1995).

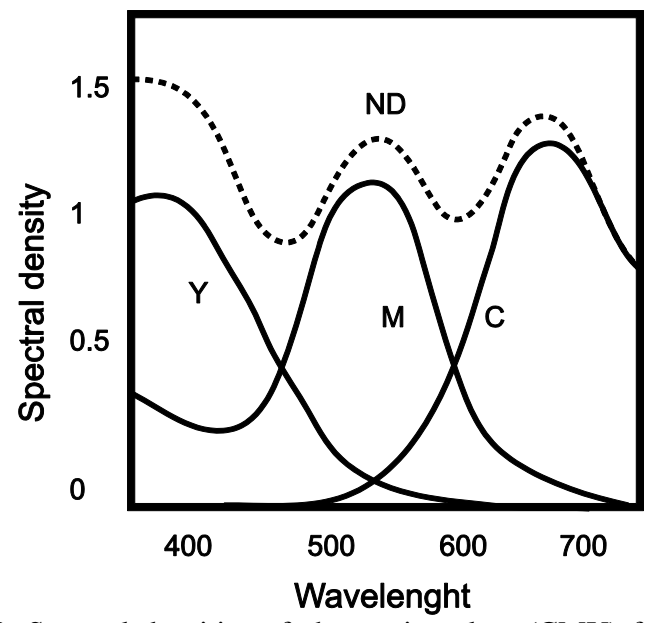

Fig. 2. Spectral densities of chromatic colors (CMY) forming mutual neutral density ND

\section{WORKFLOW AND BASIC PARAMETER SETTINGS}

The common way while determining or inspecting the reproduction process is to define some points (as densities, coverages or colorimetry values). Usually there are are at least three controls describing minimum or low values (toe of the curve) point $\mathrm{A}$, mid tone point $\mathrm{M}$, and shadow (shoulder of the curve) denoted as B. (Kodak, 1975) In observed case additional test points are designated in the A-M domain where black for skelet and full range black printer differ. The basic reproduction path (workflow) will be designated as follow:

- Imaging grey scale: Kodak grey scale reflection density guide, 24 step defined, (Kodak Q 16 target), whose density range is similar to output profile device range. Profile: adjusted euroscale coated: for first step CMY combination.

- Second step: full black scale, starting point set at $0 \%$ â at starting density. Adjusting parameters by means of Adobe CS3 support. For skelet black adjusted profile eurostandard coated, staring point $(0 \%$ â) approximate at starting density 0.4 of original, adjusting parameters by means of Adobe CS3 support. Obtaining separations and final reproduction for $\mathrm{CMY}$ and $\mathrm{CMY}+\mathrm{K}$

- Step three: controlling shadow and midtone neutral density (END and grey balance) for CMY combination

- Applying dedicated tools (wedges) to determine deviations in gained values (density, coverage, colorimetric measurements) and to adjust tone reproduction curves (TRC)

- Step four: repeated reproduction with corrected values

- checkout obtained reproduction

Output device: Epson stylus 3800, Mediaware digital photo gloss supstrate. Measaurements: Xrite i-one support The main obstacle is supposed to arise in the part where CMY coverage interfears with $\mathrm{K}$ coverage, where cumulative $\mathrm{CMY}$ and $\mathrm{CMY}+\mathrm{K}$ combination should obtain the same appearance. As the beginning of the reproduction curve (light part) is more perceptible than midtones and shadows, and black printer combination affects in that domain, this work elaborates that part of interest.

According to first results some steps had to be repeated. High values were slightly corrected to achieve balance, and that was directly done in shadows. In midtones and highlights some separate additional corrections were performed by the use of dedicated test charts, in this case adjusting neutrals.

\section{RESULTS AND DISCUSSION}

According to some additional tests it can be seen that TAC in shadows is about $300 \%$ that satisfies ISO recomendation, and allows further achromatic procedures. The primary colors ratio is nearly $1(\mathrm{C}): 0.8(\mathrm{M}, \mathrm{Y})$, that also provides grey balance.

\begin{tabular}{|c|c|c|c|c|c|}
\hline $\begin{array}{c}\text { Dn } \\
\text { orig }\end{array}$ & $\begin{array}{c}\text { Lab } \\
\text { original }\end{array}$ & $\begin{array}{l}\text { scanned } \\
\text { Lab }\end{array}$ & $\begin{array}{c}\text { CMY } \\
\text { coverage }\end{array}$ & $\begin{array}{l}\mathrm{CMY}+\mathrm{KS} \\
\text { coverage }\end{array}$ & $\begin{array}{l}\mathrm{CMY}+\mathrm{KF} \\
\text { coverage }\end{array}$ \\
\hline 0.02 & $\begin{array}{lll}97 & 0 & 0\end{array}$ & $97-1-1$ & 222 & $\begin{array}{lll}2 & 1 & 0\end{array}$ & $\begin{array}{llll}2 & 1 & 1 & 2\end{array}$ \\
\hline 0.05 & $\begin{array}{llll}93 & -1 & -1\end{array}$ & $92-1-2$ & 1144 & 1063 & $\begin{array}{llll}9 & 5 & 3 & 2\end{array}$ \\
\hline 0.10 & $91 \quad-2 \quad-2$ & $90-1-2$ & 191510 & $185 \quad 5$ & 1613113 \\
\hline 0.15 & $\begin{array}{lll}86 & -2 & -1\end{array}$ & $\begin{array}{lll}85 & 0 & -2\end{array}$ & 271916 & 282015 & 2417154 \\
\hline 0.20 & $\begin{array}{lll}82 & -2 & 1\end{array}$ & $81-1-4$ & 352620 & 342421 & 3122178 \\
\hline 0.30 & $\begin{array}{lll}75 & -2 & 1\end{array}$ & $73-1-3$ & 433430 & 4128256 & 36231912 \\
\hline 0.40 & $\begin{array}{lll}69 & -2 & 1\end{array}$ & $65-23$ & 544440 & 44363212 & 39292418 \\
\hline 0.50 & $\begin{array}{llll}60 & -2 & 1\end{array}$ & $58-3 \quad 3$ & 584947 & 51413918 & 43322718 \\
\hline 0.60 & $\begin{array}{lll}55 & -3 & -4\end{array}$ & $53-4 \quad 4$ & 675957 & 57494126 & 50423527 \\
\hline
\end{tabular}

Tab. 1. Colorimetric values of original and reproduced images for the densitometric range 0.6

Correction in midtones range was carried out for the reason that some device drivers hold the ratio (where correction would interfear basic settings, also some drivers, regardless to settings, try to perform achromatic reduction), so the correction was performed by correcting the reproduction curves. The most interesting part, highlights to midtones was separately adjusted with Gray Finder 2.0. As presented in table 1, the part of reproduction is separated to the only primaries combination (scelet, KS) and full range (KF) tones. Reproductions appear with slightly lower lightness values, separately density measured values average 0.05-0.08 lower, that can be additionaly corrected. Chromaticy coordinates render rather low values that indicate high achromacity although some authors for near to white region suggest whitness calculation, (Popson, 1997.) and metamery verification (Baumann, 2002).

\section{CONCLUSION}

For the observedconfiguration two profiles were achieved, both for the same reproduction conditions type, but different reproduction curves for the black, whereas supporting nearly the same printing effect. In defined environment that subsystem can facilitate applying different reproduction parameters, but gaining similar reproduction result.

\section{REFERENCES}

Baumann, E. (2002): Color Aspects in Photo Quality Inkjet Printing, CGIV Conference, pp 448-452, Poitiers, France.

Blair, R. (1983): The Lithographers Manual, GATF, ISBN: 088362169X Pittsburgh

Hunt, R.G.W., (1995): The Reproduction of Color, Fountain Press, ISBN: 085242356X, Tolworth

Kodak (1975): Die Maskierung mit Silbermasken nach ABM Methode, Broschüre T-5, 3-7

Popson, J. (1997): Application of Brightness, Whitness Measurement to Color Removal, 1996 Recycling Symposium Proceedings, pp. 13-18, TAPPI Press, Atlanta

Yule, J.A.C (2000): Principles of Color Reproduction, GATF Press, ISBN: 088362222X, Sweinckley 